\title{
Rapid acquisition of a sixty-carbon fullerene precursor. A new synthetic approach to $\mathbf{C}_{60}$
}

\author{
Goverdhan Mehta* and P. V. V. Srirama Sarma \\ Department of Organic Chemistry, Indian Institute of Science, Bangalore 560 012, India
} Abstract-In a new approach towards $\mathrm{C}_{60}$, two $C_{3}$-symmetric precursors having all the carbon content and thirteen rings have
been assembled in just one step from readily crafted building-blocks through threefold Wittig-Horner coupling.

Ever since its conception, ${ }^{1 \mathrm{a}}$ detection $^{1 \mathrm{~b}}$ and preparative access, ${ }^{1 \mathrm{c}} \mathrm{C}_{60} \mathbf{1}$ has enticed the synthetic community as a formidable synthetic objective. ${ }^{2}$ Devising a rational synthesis of buckyball $\mathrm{C}_{60}$, involving the generation of 32 rings and establishing $90 \mathrm{C}-\mathrm{C}$ bond connectivities, is by any reckoning a major intellectual and experimental challenge. Not surprisingly, during the past decade, many groups around the world have mobilised their ideas and resources in pursuit of a rational synthetic

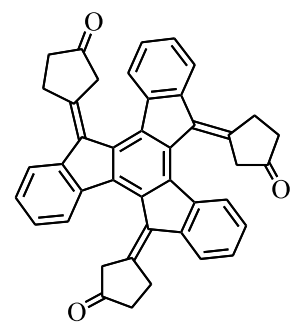

3. $\mathrm{C}_{3}-\mathrm{C}_{42} \mathrm{H}_{30}$ route to $\mathrm{C}_{60}$ and only a few months ago a synthesis, culminating in isolable amounts of $\mathbf{1}$, has been reported. ${ }^{3}$ Early synthetic efforts towards $\mathrm{C}_{60}$, emanating from triindanone derived $2, \mathrm{C}_{45} \mathrm{H}_{48},{ }^{4}$ and truxenone derived $3, \mathrm{C}_{42} \mathrm{H}_{30}$, were bold and imaginative, but did not make further headway. In another approach, several groups assembled macrocyclic polyalkyne precursors that eject multiple fragments and collapse to $\mathrm{C}_{60}$ on laser desorption/ionisation (LDI) mass spectro-

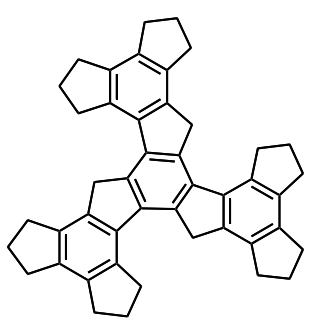

2. $C_{3}-\mathrm{C}_{45} \mathrm{H}_{48}$

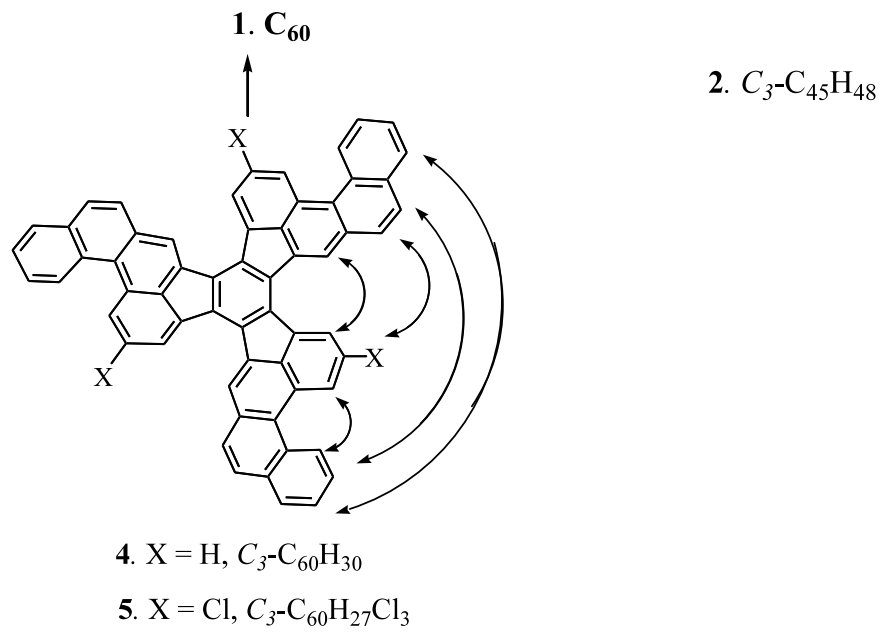

* Corresponding author. 
metry. ${ }^{6}$ However, from a preparative and classical synthesis perspective, much attention has been bestowed on $C_{3}$-symmetric precursor $4, \mathrm{C}_{60} \mathrm{H}_{30}$, which can undergo unimolecular, 15-fold tandem cyclisation (see arrows) to $\mathrm{C}_{60}{ }^{3,7}$ Indeed, laser irradiation of $\mathbf{4}$ has led to the observation of $\mathrm{C}_{60}{ }^{+}$by mass spectrometry $^{7 \mathrm{~d}, \mathrm{e}}$ and a tris-halo derivative $\mathbf{5}$ of $\mathbf{4}$ on FVP produced isolable ${ }^{3}$ quantities of $\mathbf{1}$. The key precursors 4 and 5 of $\mathrm{C}_{60}$ in turn, have been assembled through multi-step synthetic sequences. ${ }^{3,7}$

As part of our ${ }^{8}$ ongoing interest in the synthesis of buckyball 1 and its curved fragments (buckybowls), we have conceived of an approach different from oth- ers in which the novel hydrocarbon $6, \mathrm{C}_{60} \mathrm{H}_{30}$, occupies a pivotal role and can deliver $\mathrm{C}_{60}$ through 15-fold unimolecular cyclisation (see arrows), forming alternating five- and six-membered rings on FVP. The hexadecacyclic hydrocarbon 6 has an interesting propeller shaped topology as indicated by its energy-minimised structure (Scheme 1). Retrosynthetic considerations indicated that $\mathbf{6}$ can be accessed from 7 or its tribromo derivative 8 through threefold photocyclisation or intramolecular Heck coupling, ${ }^{9}$ respectively, Scheme 1. It was proposed to assemble the key $\mathrm{C}_{60}$ precursors 7 and $\mathbf{8}$ in one-step through a threefold Wittig-Horner type reaction of $C_{3}$-symmetric building-blocks.

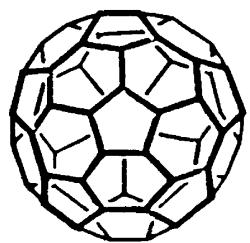

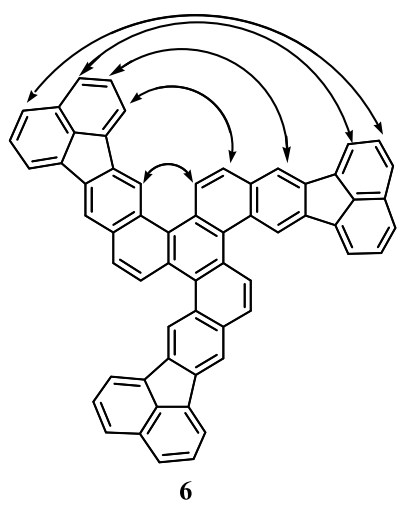

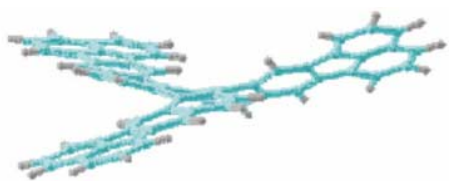

AM1 minimized structure of 6

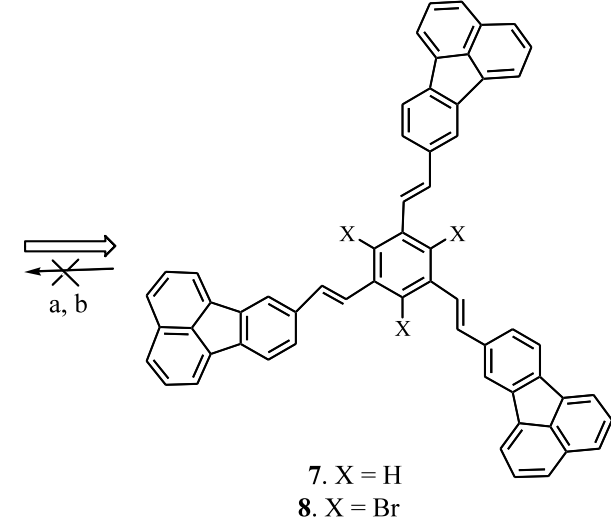

7. $\mathrm{X}=\mathrm{H}$
8. $\mathrm{X}=\mathrm{Br}$

Scheme 1. Reagents and conditions: (a) For 7. $h v$, benzene, propylene oxide, $\mathrm{I}_{2}$; (b) for $8 \mathrm{Pd}(\mathrm{OAc})_{2}, \mathrm{BnMe}_{3} \mathrm{NBr}_{2} \mathrm{~K}_{2} \mathrm{CO}_{3}, \mathrm{DMF}$, $140^{\circ} \mathrm{C}$.<smiles>[X]c1c(C)c([X])c(C)c([X])c1C</smiles><smiles>C=[18O]</smiles>

$$
\text { 12. } \begin{aligned}
\mathrm{X} & =\mathrm{H} \\
\mathrm{X} & =\mathrm{Br} \longleftarrow \mathrm{a}
\end{aligned}
$$

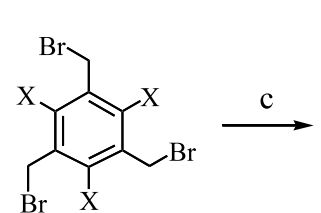

$\mathrm{X}=\mathrm{H}, \mathrm{Br}$<smiles>[X]c1c(C[Po])c([X])c(C[R]O[Na])c([X])c1C[Po]</smiles>

9. $X=H$

10. $\mathrm{X}=\mathrm{Br}$

Scheme 2. Reagents and conditions: (a) $\mathrm{Br}_{2}, \mathrm{Fe}, 59 \%$; (b) NBS, $\mathrm{AIBN}, \mathrm{CCl}_{4}, 30 \%$; (c) $\mathrm{P}(\mathrm{OEt})_{3}, 160^{\circ} \mathrm{C}, \sim 100 \%$.

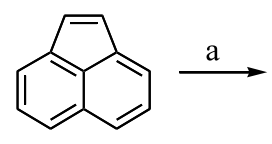

13

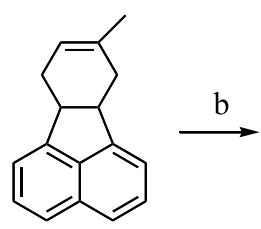$$
\mathrm{c}
$$<smiles>[X]Cc1ccc2c(c1)-c1cccc3cccc-2c13</smiles>

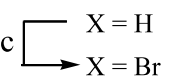

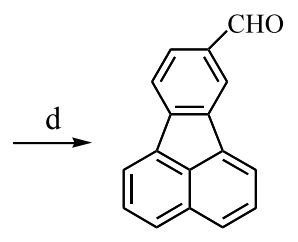

11

Scheme 3. Reagents and conditions: (a) isoprene, sealed tube, $175^{\circ} \mathrm{C}, 40 \%$; (b) DDQ, benzene, $\Delta, 70 \%$; (c) $\mathrm{NBS},(\mathrm{PhCOO})_{2}, \mathrm{CCl}{ }_{4}$, $80 \% ;$ (d) $\left(\mathrm{Bu}_{4} \mathrm{~N}\right)_{2} \mathrm{Cr}_{2} \mathrm{O}_{7}, \mathrm{CHCl}_{3}, \Delta, 86 \%$. 

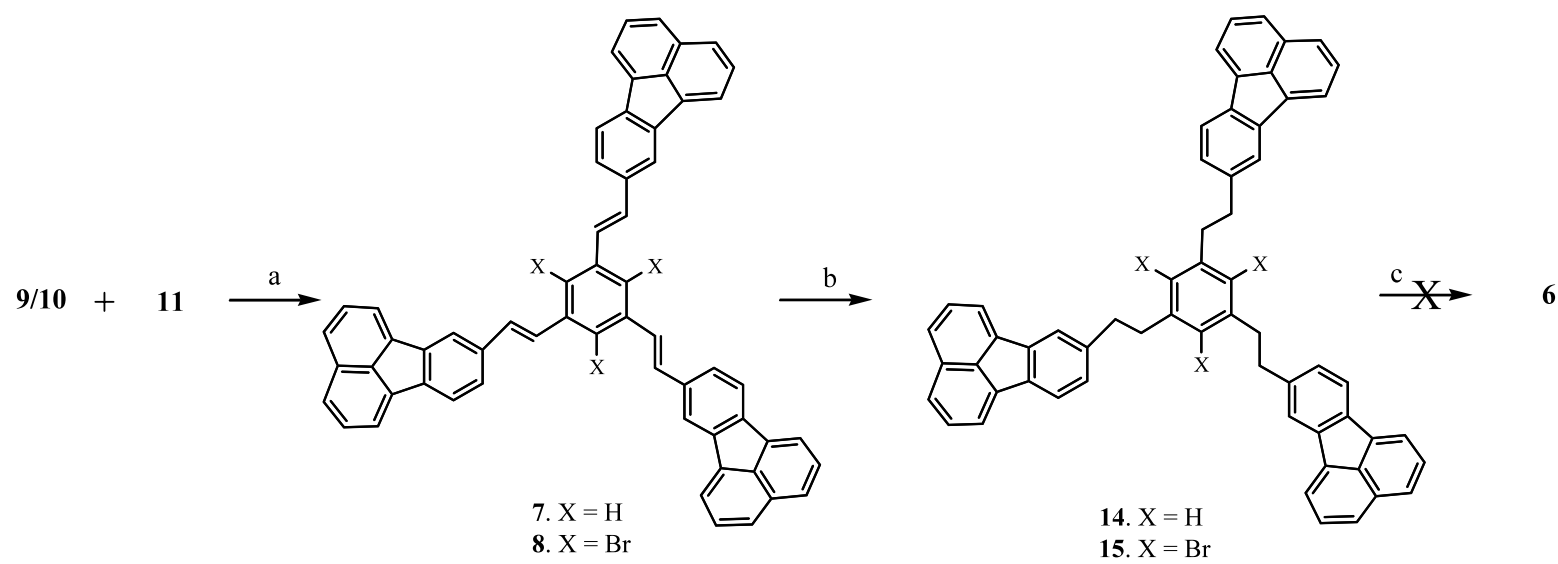

Scheme 4. Reagents and conditions: For $7 \mathrm{X}=\mathrm{H}$, (a) NaH, DMF, 4 days, 70\%; (b) 10\% $\mathrm{Pd} / \mathrm{C}, \mathrm{H}_{2}, \mathrm{EtOAc}, 60 \%$; (c) $10 \% \mathrm{Pd} / \mathrm{C}$, sealed tube, $400^{\circ} \mathrm{C}$. For $8 \mathrm{X}=\mathrm{Br}$, (a) $\mathrm{NaH}, \mathrm{DMF}, 70^{\circ} \mathrm{C}, 4$ days, $66 \%$.

For the assembly of $\mathbf{7}$ and $\mathbf{8}, C_{3}$-symmetric WittigHorner reagents $\mathbf{9} / \mathbf{1 0}$ and fluoranthene based tetracyclic aldehyde $\mathbf{1 1}^{10}$ were identified as reaction partners and were prepared from mesitylene $\mathbf{1 2}$ and acenaphthene 13, respectively, as shown in Schemes 2 and 3. Gratifyingly, threefold coupling between tris-phosphonate reagent $9^{10}$ and aldehyde 11 in the presence of $\mathrm{NaH}$ was smooth and led to $C_{3}$-symmetric all trans -7 as a bright yellow solid, Scheme $4 .{ }^{10}$ Formation of 7 was indicated by its mass spectrum (MALDI-TOF) which showed a molecular ion at $m / z 757.3 \mathrm{amu}\left(\mathrm{M}^{+}\right)$, calcd for $\mathrm{C}_{60} \mathrm{H}_{36}=756.93$ amu. While 7 was insoluble in most organic solvents, its ${ }^{1} \mathrm{H}$ NMR spectrum could be recorded in 1,1,2,2-tetrachloroethane- $d_{2}$ at $333 \mathrm{~K}$ and the characteristic $\mathrm{ABq}$ pattern centred at $\delta 7.38$ with $J=16.2 \mathrm{~Hz}$ secured the trans disposition of the olefinic bonds. However, the next critical step, the threefold oxidative photocyclisation of 7 to the desired $\mathrm{C}_{60}$ precursor 6, under a variety of conditions, met with repeated failure, Scheme 1. Attributing this failure to the inhibition of cis-trans isomerisation in 7, a necessary requirement for its photocyclisation to $\mathbf{6}$, due to steric overcrowding by the bulky benzo-fluoranthene moiety, we considered an alternative possibility. On catalytic hydrogenation 7 furnished the hexahydro product $\mathbf{1 4}$, with improved solubility in organic solvents and its 20 line ${ }^{13} \mathrm{C}$ NMR spectrum with signals at $\delta$ $38.5\left(\mathrm{CH}_{2}\right)$ and $38.2\left(\mathrm{CH}_{2}\right)$ fully secured its structure. ${ }^{10}$ As planned, 14 was subjected to cyclodehydrogenation under a variety of conditions (e.g. $\mathrm{Pd} / \mathrm{C}$ at $400^{\circ} \mathrm{C}$ ), but only fragmented products like 8-methyl-fluoranthene were isolated and the desired compound $\mathbf{6}$ was not detected.

At this stage, we turned towards 8 with the intent of effecting Heck coupling. A threefold Horner-Wittig reaction between the phosphonate ester $\mathbf{1 0}^{10}$ and tetracyclic aldehyde $\mathbf{1 1}$ in the presence of $\mathrm{NaH}$ was slow but the expected $C_{3}$-symmetric all trans tribromide $8^{10}$ was realised in reasonable yield, Scheme 4 . The mass spectrum (MALDI-TOF) exhibited the expected peak at $m / z=993.4\left(\mathrm{M}^{+}\right)$, calcd for $\mathrm{C}_{60} \mathrm{H}_{33} \mathrm{Br}_{3}=993.6$ and the ${ }^{1} \mathrm{H}$ NMR spectrum of this very insoluble material in 1,1,2,2-tetrachloroethane- $d_{2}$ at $353 \mathrm{~K}$ not only secured the structure but the $\mathrm{ABq}$ pattern at $\delta 7.12$ confirmed the expected trans disposition of the olefinic bonds. Tribromo-8 was now subjected to $\mathrm{Pd}(\mathrm{II})$ mediated Heck coupling under elevated temperature and the expectation was that under such a regime the cis-trans equilibrium might take place and cyclisation to 6 could occur. ${ }^{9}$ However, the outcome once again was disappointing. An obvious option at this stage was to reduce the olefinic double bonds in $\mathbf{8}$ to hexahydro-tribromide $\mathbf{1 5}$ and then attempt a Heck coupling as was demonstrated by us recently in similar systems. ${ }^{9}$

However, the seemingly straightforward reduction of the double bonds in $\mathbf{8}$ could not be achieved despite many efforts. It appears that the high insolubility of this substrate in most organic solvents is detrimental to its further evolution and efforts are underway to overcome this problem.

In short, we have rapidly assembled $7\left(\mathrm{C}_{60} \mathrm{H}_{36}\right)$ and 8 $\left(\mathrm{C}_{60} \mathrm{H}_{33} \mathrm{Br}_{3}\right)$ having the full carbon content of $\mathrm{C}_{60}$ and embedding thirteen rings in just one-step through Wittig-Horner reactions on appropriately crafted partners. Although, the proposed transformation of $\mathbf{7}$ and 8 to $\mathbf{6}$ has not been successful so far, the ready availability of precursors $\mathbf{7}$ and $\mathbf{8}$ is significant and provides stimulus for further efforts towards $\mathrm{C}_{60}$.

\section{Acknowledgements}

We would like to thank the SIF at IISc for providing high field NMR data. One of us (P.V.V.S.S.) thanks CSIR for the award of a research fellowship.

\section{References}

1. (a) Osawa, E. Kagaku 1970, 25, 854; (b) Kroto, H. W.; Heath, J. R.; O’Brain, S. C.; Curl, R. F.; Smalley, R. E. Nature 1985, 318, 162; (c) Kratschmer, W.; Lamb, L. D.; Fostiropoulos, K.; Huffman, D. R. Nature 1990, 347, 354. 
2. For reviews, see: (a) Mehta, G.; Rao, H. S. P. Tetrahedron 1998, 54, 13325; (b) Mehta, G.; Rao, H. S. P. In Advances in strain in Organic Chemistry; Halton, B.; Ed.; Jai Press: London, 1997; Vol. 6, pp. 139-187; (c) Scott, L. T.; Bronstein, H. E.; Preda, D. V.; Ansems, R. B. M.; Bratcher, M. S.; Hagen, S. Pure Appl. Chem. 1999, 71, 209.

3. Scott, L. T.; Boorum, M. M.; McMahon, B. J.; Hagen, S.; Mack, J.; Blank, J.; Wegner, H.; de Meijere, A. Science 2002, 295, 1500.

4. Fabre, C.; Rassat, A. CR Acad. Sci., Sec. 2 1989, 308, 1223.

5. Loguercio, D., Jr. Studies towards a convergent synthesis of $\mathrm{C}_{60}, \mathrm{Ph} . \mathrm{D}$. Thesis, UCLA, 1988.

6. (a) McElvany, S. W.; Ross, M. M.; Goroff, N. S.; Diederich, F. Science 1993, 259, 1594; (b) Rubin, Y.; Parker, T. C.; Pastor, S. J.; Jalisatgi, S.; Boulle, C.; Wilkins, C. L. Angew. Chem., Int. Ed. Engl. 1998, 37, 1226; (c) Tobe, Y.; Nakagawa, N.; Kishi, J.; Sonoda, M.; Naemura, K.; Wakabayashi, T.; Shida, T.; Achiba, Y. Tetrahedron 2001, 57, 3629 and references cited therein.

7. (a) Plater, M. J. J. Chem. Soc., Perkin Trans. 1 1997, 1 , 2897; (b) Sarobe, M.; Fokkens, R. H.; Cleij, T. J.; Jenneskens, L. W.; Nibbering, N. M. M.; Stas, W.; Versluis, C. Chem. Phys. Lett. 1999, 313, 31; (c) GomezLor, B.; de Frutos, O.; Echavarren, A. M. Chem. Commun. 1999, 2431; (d) Boorum, M. M.; Vasil'ev, Y. V.; Drewello, T.; Scott, L. T. Science 2001, 294, 828; (e) Gomez-Lor, B.; Koper, C.; Fokkens, R. H.; Vlietstra, E. J.; Cleij, T. J.; Jenneskens, L. W.; Nibbering, N. M. M.; Echavarren, A. M. Chem. Commun. 2002, 370.

8. (a) Mehta, G.; Shah, S. R.; Ravikumar, K. J. Chem. Soc., Chem. Commun. 1993, 1006; (b) Mehta, G.; Rao, K. V.; Ravikumar, K. J. Chem. Soc., Perkin Trans. 1 1995, 1787; (c) Mehta, G.; Rao, K. V. Synlett 1995, 319; (d) Mehta, G.; Sharma, G. V. R.; Kumar, M. A. K.;
Vedavyasa, T. V.; Jemmis, E. D. J. Chem. Soc., Perkin Trans. 1 1995, 2529; (e) Mehta, G.; Panda, G. Tetrahedron Lett. 1997, 38, 2145; (f) Mehta, G.; Panda, G.; Shah, S. R.; Kunwar, A. C. J. Chem. Soc., Perkin Trans. 1 1997, 2269; (g) Mehta, G.; Panda, G. Chem. Commun. 1997, 2081; (h) Mehta, G.; Panda, G.; Sarma, P. V. V. S. Tetrahedron Lett. 1998, 39, 5835; (i) Mehta, G.; Panda, G. Proc. Ind. Natl. Sci. Acad. 1998, 64A, 587; (j) Mehta, G.; Sarma, P. V. V. S. Chem. Commun. 2000, 19.

9. Mehta, G.; Sarma, P. V. V. S. Tetrahedron Lett. 2002, 43, 6557.

10. All new compounds reported here exhibited satisfactory spectral characteristics. Selected spectral data: 7: $\mathrm{mp}$ $>350^{\circ} \mathrm{C}$, UV $\left(\mathrm{CHCl}_{3}\right): \lambda_{\max }=242,332$ and $379 \mathrm{~nm}$; IR (KBr): 3037, 2923, 1584, 1457, $954 \mathrm{~cm}^{-1} ;{ }^{1} \mathrm{H}$ NMR $(300$ $\left.\mathrm{MHz}, \mathrm{C}_{2} \mathrm{D}_{2} \mathrm{Cl}_{4}, 333 \mathrm{~K}\right): \delta 8.17(\mathrm{~s}, 3 \mathrm{H}), 8.05(\mathrm{~d}, 3 \mathrm{H}$, $J=6.6 \mathrm{~Hz}), 7.98-7.86(\mathrm{~m}, 12 \mathrm{H}), 7.72(\mathrm{~s}, 3 \mathrm{H}), 7.72-7.61$ $(\mathrm{m}, 9 \mathrm{H}), 7.42$ and $7.34(\mathrm{ABq}, 6 \mathrm{H}, J=16.2 \mathrm{~Hz})$; $\mathrm{MS}$ (MALDI-TOF): $m / z=757.3\left(M^{+\bullet}\right)$, calcd for $\mathrm{C}_{60} \mathrm{H}_{36}=$ 756.93; 8: $\mathrm{mp}>350^{\circ} \mathrm{C}$, UV (1,1,2,2-tetrachloroethane): $\lambda_{\max }$ 254, 296, 349 and $365 \mathrm{~nm}$; IR (KBr): 3041, 1457, 963, $766 \mathrm{~cm}^{-1} ;{ }^{1} \mathrm{H}$ NMR (300 MHz, $\left.\mathrm{C}_{2} \mathrm{D}_{2} \mathrm{Cl}_{4}, 353 \mathrm{~K}\right): \delta$ $8.15(\mathrm{~s}, 3 \mathrm{H}), 8.05(\mathrm{~d}, 3 \mathrm{H}, J=6.6 \mathrm{~Hz}), 7.99-7.86(\mathrm{~m}, 12 \mathrm{H})$, 7.70-7.60 (m, 9H), 7.20 and $7.05(\mathrm{ABq}, 6 \mathrm{H}, J=16.5 \mathrm{~Hz})$; MS (MALDI-TOF): $m / z=993.4 \quad\left(M^{+}\right)$, calcd for $\mathrm{C}_{60} \mathrm{H}_{33} \mathrm{Br}_{3}=993.6 ; 14: \mathrm{mp} 180^{\circ} \mathrm{C}$, IR (KBr): 3040, 2918, 1601, 1456, $769 \mathrm{~cm}^{-1} ;{ }^{1} \mathrm{H}$ NMR (300 MHz, $\left.\mathrm{CDCl}_{3}\right): \delta$ 7.88-7.74 (m, 15H), 7.63-7.57 (m, 9H), $7.09(\mathrm{~d}, 3 \mathrm{H}$, $J=6.3 \mathrm{~Hz}), 6.92$ (s, 3H), 2.97 (brs, 12H); ${ }^{13} \mathrm{C}$ NMR $(75$ $\mathrm{MHz}, \mathrm{CDCl}_{3}$ ): $\delta 141.8$ (3C), 141.6 (3C), 139.7 (3C), 137.3 (3C), 137.1 (6C), 132.7 (3C), 130.0 (3C), 128.0 (3C), 127.9 (6C), 126.6 (3C), 126.5 (3C), 126.2 (3C), 121.8 (3C), 121.3 (3C), 119.9 (3C), 119.6 (3C), 38.5 (3C), 38.2 (3C); MS $(\mathrm{m} / z)$ : $762\left(\mathrm{M}^{+\bullet}\right)$. Anal. calcd for $\mathrm{C}_{60} \mathrm{H}_{42}: \mathrm{C}, 94.45 ; \mathrm{H}$, 5.55. Found: C, 94.65; H, 5.58. 